Boise State University

ScholarWorks

4-1-2011

Getting to the Real Story: What Vietnamese Business People Wish Foreigners Understood About Doing Business in Emerging and Transition Countries Like Vietnam - BEFORE They Start

Nancy K. Napier

Boise State University

Vuong Quan Hoang

DHVP Research \& Consultancy 


\title{
Getting to the Real Story: What Vietnamese Business People Wish Foreigners Understood About Doing Business in Emerging and Transition Countries Like Vietnam - BEFORE They Start
}

\author{
Nancy K. Napier \\ Boise State University \\ Vuong Quan Hoang \\ DHVP Research \& Consultancy
}

\begin{abstract}
Knowledge sharing typically examines organizational transfer of knowledge, often from headquarters to subsidiaries, from developed country sites to emerging country sites, or from host to local employees. Yes, recent research, such as Prahalad's Bottom of the Pyramid, raises the question of reverse transfer of knowledge, or whether knowledge could and should be transferred from local sites to home country sites within an organization. As several emerging economies build their capabilities in knowledge, research and development, marketing, and the like, it only makes sense to consider what type of knowledge and how to transfer it in reverse or bi-directional manners.

This reflection paper takes one step back in the process. Rather than focusing on what knowledge transfer may make sense within an organization, we consider, through a series of small case studies and experience, what types of knowledge are important for foreigners to know at the initial stages of engagement abroad as they consider whether to do business in an emerging country.
\end{abstract}

Knowledge sharing has traditionally referred to within organizational transfer of knowledge, often from headquarters to subsidiaries, from developed country sites to emerging country sites, or from host to local employees. Recent research has sought to consider human resource management and knowledge transfer may be changing in fast paced environments, particularly in emerging economies (e.g., Harvey, Kiessling, and Novicevic, 2003; Miesing, Kriger, and Slough, 2007; Napier, 2005, 2006; Prahalad,2004) raise the question of reverse transfer of knowledge, or whether knowledge could and should be transferred from local sites to home country sites within an organization. As several emerging economies build their capabilities in knowledge, research and development, marketing, and the like, it only makes sense to consider what type of knowledge and how to transfer it in reverse or bi-directional manners (Napier, Harvey and Usui, 2008).

This paper takes one step back in the process. Rather than focusing on what knowledge transfer may make sense within an organization, we offer observations about selected types of knowledge that would be important for foreigners to know at the initial stages of engagement abroad as they consider whether to do business in an emerging country. Much research has focused on what cultural aspects foreigners need to know before leaving for an assignment abroad (e.g., Vance and Paik, 2002; ) working abroad focuses on what training they need before

For this paper, Vietnam is the country of focus for several reasons. First, it is one of the fastest growing investment destinations in the world. According to a survey of global investors by UK Trade and Investment and the Economist Intelligence unit, for the third year in a row, Vietnam was rated the top investment location after the BRIC countries. (http://www.ukti.gov.uk/uktihome/media/pressRelease/117708.html). The more than 520 global executives who were surveyed ranked Vietnam as the \#2 investment destination after China for the coming two years. In addition, the survey also notes that local companies in those emerging countries are key for global firms seeking partnerships and alliances, meaning that the demand for local knowledge is crucial for success. Also, academic research has begun to blossom on Vietnam in recent years (e.g., Giroud, 2007; Napier and Thomas, 2004; Quang, Swierczek, and Chi, 1998; Vo, 2009). 
In addition to these reasons for examining the conditions in Vietnam, the authors also bring unique expertise. One is a Vietnamese business manager/entrepreneur and consultant who has extensive experience working with local and foreign firms. As a result, he has worked with many foreigners in a variety of business fields. During those years, he has encountered many knowledge gaps in people who seek to do business in his country. The other author is an American, who has worked in Vietnam since 1994 in educational and business sectors, and has written and examined notions of reverse and bi-directional knowledge transfer within organizations. Thus, both of us have experience on the past and current business conditions of this fast paced emerging economy, and of how to transfer knowledge both directions. This paper, however, has pushed us to think very practically about the types of knowledge important for foreigners to understand as they engage with potential Vietnamese business partners.

Finally, research on what foreigners and expatriates need to know before and during their time in a host country (e.g., Bjorkman and Ehrnrooth, 1999; Napier and Thomas, 2004; Thomas and Ravlin, 1995; Vance and Paik, 2005) often takes the foreigner's perspective. Less research (e.g., Vance and Paik, 2002; Vo, 2009) looks at what the host country employees might need or be able to teach expatriates. This paper, then, offers suggestions, based primarily upon in country experience, case examples of successes and failures to look at what information may be available and useful coming from within an emerging country. Given its more macro focus, the paper moves beyond what cross-cultural management researchers would typically focus on - learning and understanding cultural differences to business aspects, which of course embed culture as well.

\section{Doing Business in Vietnam: Oh, if Only Those Foreigners Understood....}

In this section of the paper, we examine five broad areas where Vietnamese business people frequently bemoan the fact that foreigners do not quite understand the local conditions when they seek to do business in the country. In particular, the selected areas focus on understanding (1) the notion of who does what and "seed capital;" (2) "disguised entrepreneurs;" (3) strategic planning and consultants; and (4) different perspectives on human resource management; and (5) the role of strategic partners. As Granted, several of these observations are not unique to Vietnam but are common across emerging economies generally. Yet, if they are relatively common, experience in Vietnam then offers the opportunity to look at some macro issues that any foreign manager in an emerging economy may face. Of course, some aspects are Vietnam-specific, because of history or cultural influences, and we point those out within the segments below.

Vietnam's history is long, complex, and can be confusing to foreigners. Key elements, though, can help potential businesspeople who wish to do business with the Vietnamese. First, the people have been influenced by a Confucian culture, including the importance of hierarchy and saving face, by a history that has included long stretches of being invaded by others, leading to some distrust by outsiders. Indeed, the last 35 years has been one of the country's longest periods without war. Finally, the differences between the north and south, in terms of the view of money, savings, and entrepreneurship all affect the interaction between business people in Vietnam and foreigners.

\section{Understanding who does what and "seed" capital}

Most Vietnamese business people are enthusiastic about discussing collaboration opportunities. Their overenthusiasm, however, sometimes leads to their partners' misunderstanding, especially when the partners are foreigners. Many Vietnamese people have a perception that foreigners bring not only future profits but also immediate revenues. If a foreigner overlooks this expectation for quick returns and revenue, then the highly potential collaboration may stumble or perhaps evaporate all together. So why the misunderstanding?

A foreigner who comes to Vietnam is pleased when he finds what he considers to be the right local counterpart who well understands the local market. The foreigner is happy to learn market insights from his partner, which typically happens verbally at meetings and dinners. However, there comes the time when the foreign investor needs concrete facts and figures to develop a careful business plan for the new venture into Vietnam's market. Since he considers the business plan as a prerequisite for mutual benefits, the foreigner often expects his Vietnamese partner to provide such information and data. In other words, the foreigners often expect that the local partners will conduct market research (often at no cost) as part of what they bring to the budding relationship. The Vietnamese business people typically do not think this is appropriate but, for cultural reasons, they rarely ask for payment. Sometimes they 
expect that the foreigner will offer (some payment) but when he does not, thus comes the first opportunity for misunderstandings and chance for a lost partnership.

The typical scenario is that the foreign partner expects the Vietnamese partner to conduct marketing research as well as other tasks, like checking legal questions or arranging key meetings, as part of the contribution to the new relationship. While foreigner may not expect that the Vietnamese partner will cover ALL the costs in this preparation stage, he very likely will consider many of the tasks as part of a "joint venture," and thus anticipate that the Vietnamese side will cover the costs incurred in Vietnam, at a minimum. The foreigner, for his part, expects to take responsibility for tasks and costs that happen outside of Vietnam. Given that quid pro quo expectation on the foreigner's part, he misses the undercurrent resentment. At base, the Vietnamese partner may simply consider the costs, from his perspective, to be too high in relative terms. Also, the Vietnamese may wish (expect?) the foreigner to offer some immediate (even if small) revenues to the partnership, by paying for some of the onsite work. If that happens, the Vietnamese consider it as signal of goodwill and serious collaboration.

So what's behind this? The Vietnamese partner has knowledge of the local market and considers that knowledge to be an asset for the potential partnership (Nguyen, Giang, and Napier, 2001). But because conducting thorough market research or initiating a new business incurs expenses, he will be reluctant to do too much without some financial incentive. Thus, on the one hand, the Vietnamese partner wants to capitalize on this knowledge asset and feel it has financial value to the foreign partner. Also, since the Vietnamese partner may perceive that he faces above-average expenses when entering a foreign partnership, both in form and substance, he will wish for some upfront support. At a minimum, the Vietnamese partner expects the foreign partner to cover or at least share the costs associated with marketing research. When they calculate what the foreigner is already spending to look at opportunities in Vietnam, the Vietnamese business partner then becomes frustrated. That is, the Vietnamese partner calculates that the foreigner spends more on his airfares, hotels, and food than what it would cost in Vietnam to pay for collecting information, gathering important contacts, exploring legal procedures, and the like. But if the foreigner does not offer to pay, and the Vietnamese is saving face by not asking for pay, no one mentions the issue directly. This stems from a long term cultural influence in Vietnam, in which hierarchy plays in stronger, placing the Vietnamese at a somewhat vulnerable position relative to what he may perceive as the more powerful foreigner in the relationship ( $\mathrm{Vu}$ and Napier, 2000). The disappointing and baffling result: the foreigner waits for Vietnamese inputs while the Vietnamese waits for financial support. Cooperation stalls, and often the foreigner has no idea why.

To avoid this situation, the foreigner should proactively ask his partner about cost-sharing policies. Because many Vietnamese businesses are frequently in short financial positions, they will appreciate it greatly if the foreign partner helps support the upfront activities. Sometimes, the burden can often be relieved by a surprisingly small amount of "seed capital" funding to begin a fruitful business and partnership. Thus, before pursuing and acknowledging a full partnership, a wise foreign investor may appoint his Vietnamese counterpart as a liaison or representative office, and help fund the operation's expenses to conduct initial steps. This option truly ensures the mutual benefits.

In addition to understanding the financial expectations and obligations on both sides, the foreigner needs to understand fully the role of the potential partner. This ties in with the next section, where we discuss the idea of a "disguised entrepreneur," or "middle man." Critical in choosing a partner at any stage is the importance of finding out what the partner can and will do. Many Vietnamese business people will approach a foreigner with ideas for investment and collaboration. Oftentimes flattered, the foreigner without much understanding may "fall for" what sounds like an unusually lucrative opportunity. The foreigner should always find out what the potential partner has completed and how he has followed through on other projects. Often there is a gap between what the local partner proposes what he has done or is able to do. Thus, it is critical for the foreigner to find some type of trustworthy "cultural or business interpreter," who can help deconstruct the reality.

The "cultural interpreter" should be a local professional business and consulting firm, which has an understanding and expertise of the business and administrative processes, freeing the foreigner from some of the paperwork burden. The knowledge and skill of the consultant in Vietnam comes in knowing the right person in the administration who is in charge of some procedures (e.g., issuing an investment license) as well as how to build a relationship with him (or her). This type of consulting business is now maturing in Vietnam since public administration reform program is progressing. 


\section{Understanding the "disguised entrepreneur" or "middle man" role}

Most Vietnamese businesses are small and medium enterprises, a fact that is often used as an evidence of strong and dynamic entrepreneurship in Vietnam. But there is also a vibrant group of so-called "disguised entrepreneurs."

When a foreigner comes to Vietnam, her Vietnamese counterpart may persuade her that "this" is the right time to go after an opportunity and set up a business firm in the emerging market. Assuming the potential foreign partner understands the need for initial financial support to conduct market studies, and assuming the economic environment looks promising, a specific project or business may emerge as a possible opportunity. But after the initial period, when the Vietnamese counterpart turns to the foreigner and says, "NOW it is time for partner selection," no wonder the foreigner is perplexed. Sometimes the foreigner may feel she is being "handed off" or that the initial relationship was not transparent. Yet, it is more a case of different business practices, than underhanded actions.

So why such a shift at this stage? Rather than assuming that the initial "partner" will be the long term partner, which may be the case in other countries, the Vietnamese approach the process differently. Instead of the "first" Vietnamese counterpart being the eventual partner, in fact, that person will want to introduce other local candidates who are more suitable as partners for the long term project or specific business opportunity. Behind this is a preference that many Vietnamese business people have to being a "middle man" rather than to being the primary partner on a project or new business venture. These middle men, who make connections for entrepreneurial ventures are called, in Vietnam, "disguised entrepreneurs." They favor being on the "safe side" - just making connections - rather than taking overt financial risks or facing other uncertainties, even if they forgo possible profits.

The benefits for these disguised entrepreneurs who assist foreigners in selecting the "real" partners are many. First, they gain immediate revenues by facilitating the discussion and negotiation process. To this end, however, it is important to understand the distinction between these "disguised entrepreneurs" and professional service providers, namely consulting firms. The disguised entrepreneurs seek not only financial but also intangible gains. The intangible gains are business relationships that may extend to future business opportunities and branding effects. The Vietnamese middle man needs a good reason to approach the other potential partners, especially the bigger or stronger Vietnamese corporations. Thus, introducing a high-profile international counterpart to a large Vietnamese firm builds the disguised entrepreneur's brand and credibility. This process of facilitating partners "finding" each other allows the middle man to expand his business relations. In addition, if he does a good job for the international counterpart in seeking local partners, he will likewise expand his own "international" brand.

Second, since the disguised entrepreneurs are involved in the project at its initial stage, they may contribute many ideas to the future business, even though they will not be involved in the implementation of those ideas. Thus, they gain status (and intrinsic satisfaction) in being listened to but also in seeing, over time, some of their ideas or dreams become true, and they do this without taking the risks involved in making those ideas happen. Finally, some argue that the disguised entrepreneurs feel more respected simply by being part of the early discussions with foreigners. Although his business is small, and his resources are very limited, the middle man often can bring an abundance of business ideas. (In fact, one of his problems may be having too many good ideas.) In most cases, this disguised entrepreneur wants to implement these ideas but, because of his unwillingness to take risks or the lack of financial resources, he cannot or does not. Thus, by offering ideas to the foreign investor, he has the opportunity to see some of the ideas implemented. This makes for a schizophrenic position at times: on the one hand, the middle man wants to claim some ownership of the business ideas he proposes; conversely, however, he is risk adverse when it comes to implementing those concepts.

Despite this perhaps confusing state for the foreign partner, a Vietnamese middle man partner is useful for the foreigner because he is willing to facilitate the success of the new business or project without expecting major financial returns. However, because the middle man typically lacks professional capacities to support investment facilitations, he may feel left "out of the game." And this conjures up yet another danger spot for the foreign investor. If the middle man feels threatened (i.e., that the foreign investor naturally begins to listen to the new "nondisguised" partner, the middle man may react in negative ways. While he may sincerely wish and seek to find a very good Vietnamese partner for the foreign investor, he nevertheless wishes to continue in a significant role for the foreigner and may fear that the new Vietnamese partner will (appear to or) be perceived by the foreigner as much better than he is. As most outsiders would fully expect, the strength of the new partner may reduce the perceived value of the middle man. In some cases, and not all that infrequently according to Vietnamese partners and 
consultants, the middle man may seek to maintain a strong role by pointing out weaknesses and disadvantages of the very partner he has recommended to the foreigner. From the foreigner point of view, this can be disconcerting and confusing at the very least, and perhaps even frustrating enough to want to pull completely away from the middle man. Yet, Vietnamese experts argue that at this stage, the middle man could indeed do serious damage so the best tactic for the foreigner is to repeatedly affirm that the middle man is still an important member of the team.

\section{Understanding Strategic Planning and the Use of Consultants}

The notions of corporate strategy and long-term planning are somewhat new in Vietnam, and hence strange and unrealistic, to much of the business community there. Coupled with the expense of conducting long term planning projects, many Vietnamese business people eschew the idea of using outsiders at all. Yet, many managers set up and start running a new company with a list of wishes but with no business plan. Recently, some large corporations in Vietnam have embraced the concept of doing "big things," thinking globally, and developing strategy. These are positive signals that the local business society is stronger and integrating well into global business and systems. However, it is unclear whether these corporations are truly aware of their needs and what it means to have a thoughtful business strategy.

As with so much in Vietnam, what appears to foreigners on the surface to be a positive market may underneath be something quite different. The misunderstandings often come when the expectations of the parties differ significantly and the foreign consultant or professional firm is unable to get to the true reason for an engagement. The most common reason for hiring foreign consultants appears repeatedly - to have the cache of the international brand involved with the firm. This, of course, often means that the content and the results from the foreign consultant work is less important.

Yet, foreign professionals and consultants can find a huge market for strategic management consultancy in Vietnam, and surprisingly, often very generous budgets for such projects. Multi-million dollar contracts for corporate restructuring and/or strategic planning are increasingly popular. For example, in 2010, VIB Bank signed a multimillion dollar consulting contract with the Boston Consulting Group.

Interestingly, however, some of the Vietnamese business people who pay high prices for foreign consultants seem relatively unconcerned about the quality of services. At present, the focus is more on gaining the notoriety and recognition that comes from engaging the services of a well-known international team of consultants with high brand recognition, including some well-known experts or professors. Gaining the recognition, for some Vietnamese corporations, appears to be far more important than the exorbitant fees demanded by the international consultants.

Although such an environment sounds like heaven for a foreign consulting firm seeking to do business in Vietnam, as always, consultants need to be aware of the unseen and likely unmentioned expectations of such programs. The most important rule to remember in the current strategic planning consulting environment in Vietnam is that the business owner very likely has already set his own strategy and ideas, and the consultant's job is to describe those (perhaps unwritten) plans professionally, internationally, and globally. In other words, rather than create a good strategy for the firm, the consultant's job in reality is to support the owner's ex-ante strategy. Thus, misunderstandings sometimes occur.

For example, a Vietnamese business owner may request a foreign consulting firm to conduct a feasibility study on factory expansion. A service contract is prepared by both sides, and the relationship appears friendly and cooperative. However, early on, the two parties disagree on the definition of how to measure the accomplishment of the project's mission. The foreigner defines accomplishment and completion as the submission of a feasibility report that is approved by the business owner. In the report, the foreign consultant expects to provide a recommendation of whether the Vietnamese firm should expand the factory or not. The business owner, on the other hand, considers the project's mission complete when shareholders agree on the expansion plan of the factory (regardless of the consultant's recommendations to expand or not) and expects a much more extensive involvement from the consultant in helping to "sell" the shareholders on the expansion, which may in fact go against the consultant's recommendation. Thus foreigners, especially consultants, need to understand that a challenge in providing consulting services in Vietnam is not pricing services or showing clients how cleverly the consultant analyzed the problem, but to understand whether the clients have their own solutions before the project even begins, and what that could mean for the project's success. This, of course, is not only common in Vietnam but also in developed 
countries, among a wide range of firms that hire consultants. Yet, once again, the consultant needs to understand the "real" reasons behind a Vietnamese firm's request for services.

\section{Understanding different perspectives and roles of "human resource management"}

A foreigner may also face confusion about human resource management issues that seem different from the ways they may be approached in her home country. Examples follow.

Employees may lack the ability to conduct cost-benefit analysis, even for themselves. When assigning an employee to a job, a human resource (HR) manager obviously wants to find the right match of skills and job, but also seeks someone who wants to hold the position. In other words, the best situation is to find an employee who is selfmotivated to do a good job, perhaps because it fulfills a personal goals. Some people argue that Vietnamese people lack an ability to carry out cost-benefit analysis in their decision making, whether when choosing a job or assessing a business opportunity. Perhaps because in the past, many employees have not been required to make decisions, but rather have been "told what to do," at home, school, and at work, they may be unable to fully assess the benefits (or costs) of a new job when offered. Thus, sometimes a foreigner may offer a position but find the Vietnamese recipient hesitant or uncertain about how to analyze the opportunity, let alone make a decision. In such a situation, the Vietnamese HR manager, or perhaps even the CEO, must explain to the employee the benefits - and the drawbacks -- of a job. Thus, instead of being a referee of the competition for the position, the HR manager or CEO may become more of a "salesperson" and negotiator with prospective employees.

Further, since Vietnamese perceive that foreign firms tend to offer high salaries, have nice facilities (e.g., computers, air conditioning, pleasant surroundings), and a professional working environment, recruiting local Vietnamese staff members can be relatively easy for foreigners. The applicants mostly think of benefits, not costs, when applying to a foreign firm. Thus, the senior managers need to be sure the costs or drawbacks are considered, to make the decision for the employee one that is based upon "reality." This weak ability to assess costs and benefits can, of course, be a real problem at higher level jobs, especially when foreigners seek Vietnamese for mid-management positions. Since those will inherently require an ability to carry out independent cost-benefit analysis in decision making, as well as some strategic vision, foreigners may need to build in training to help employees learn the skill.

Short-sightedness. A weak ability to do cost-benefit analysis may go along with short-sighted thinking, which can translate into frequent employee turnover. A human resources manager may experience high levels of "people-in and people-out," disrupting any hope of a stable work force. This pattern is new to Vietnam, a country where simply having a job, and staying with it regardless of conditions, was the accepted pattern for years.

While foreigners may encounter similar upheaval in the home country, it seems especially strong in Vietnam at present, in part because of some of the other comments we referred to above (e.g., desire for quick returns, building brand image, using international / foreign partners as a way to gain status). The same is likely true about some Vietnamese employees. In addition, young Vietnamese talent increasingly expect that after several years of training on job, they will receive the mantle of management and demand more benefits. Not unlike the Millennial Generation in the U.S., the younger employees begin demanding higher benefits "now, immediately." When the expected benefits are not forthcoming, they leave for a competitor, potentially kicking off a "labor war," making doing business in Vietnam more costly. Such a result, of course, is no good for the foreign firms or the Vietnamese economy.

Perception of team-work and professionalism. The Vietnamese perceive team-work and professionalism differently than Western people. While foreigners who have read about the "collective" culture assume that Vietnamese work well in groups, there is a definite distinction between group and team. In fact, one often used phrase is that the Vietnamese are "groups called teams" (Vu and Napier, 2000). Teamwork, for Vietnamese, is dividing the work into different parts and every team member does his or her part separately, with limited coordination. There is, of course, a team leader who is in charge of collecting individual results and merging them, but the individual members work in parallel with no sense of working together toward a common goal. Therefore, foreigners need to be aware, even if they have highly qualified individual staff members, there will likely be a lack of "natural" teamwork and may need to explicitly develop that skill within the firm. 
As to professionalism, some Vietnamese perceive and value form over the substance. A "professional" is person who wears suit, uses a modern laptop, speaks a foreign language, sits in high-rise building, and drives a car. Rather such skills as writing an email with correct grammar, preparing meeting documents to be flawless, or presenting an attractive power-point overview, are considered less important than what may be accepted as common expectations in a foreign context. Therefore, a foreigner should pay much more attention to what people really do than what they show. A Vietnamese may truly believe in his professionalism because he has a new Sony Vaio, but he may use it more for chatting, watching online movies and playing games than for work related activities.

Skill and behavior at work. Despite what may seem like deficiencies in the Vietnamese workforce, the people are quite smart and good learners. So when recruiting staff members, foreigners should worry less about applicants' skills, which can be trained, than about their ways of thinking -- their jobs, their work, and their colleagues. Some Vietnamese hear foreigners lament that they have tried their best to find good employees but then, metaphorically, throw up their hands and ask: "can they think correctly?" or even worse, "can they think?" While good operational and human resource management guidelines may help, most important is seeking and finding employees who are willing and able to take responsibility, accountability and have "good thinking capacity" - no different from what they desire in their home countries, but perhaps a bit harder to "see" clearly in another culture.

\section{Understanding the Role of Strategic Partners}

Many Vietnamese business people longingly remember the stock mania of 2006-2008. The Vietnamese Index (VNIndex) rocketed from 503 points on March 3, 2006, to the peak of 1,171 on March 12, 2007. While flocking into stock transactions, the Vietnamese - like so many others around the world -- fully believed in the rising trend of stock prices (Vuong, 2010). So, given the fast pace of mergers, acquisitions, or alliances, and the interest of foreigners in entering Vietnam, it is critical to understand just what the role is for those foreign strategic partners.

The surge of the Vietnamese stock markets caused a second wave of foreign portfolio investment to Vietnam. In 2006-2008, 20 new investment funds were initiated. The State Securities Commission of Vietnam also licensed 17 fund management companies in the same period. Essentially, such optimistic signs in the Vietnamese economic development buoyed the international financial community's outlook on the country and its investment opportunities. Large investment firms like Merrill Lynch, Goldman Sachs, and J.P. Morgan Chase entered Vietnam (Vuong and Tran, 2009), anticipating a stable macro economic environment and active entrepreneurial community that would support Vietnam as a destination for investment funds. Like much of the rest of the world, it was a spectacular time for investing, and Vietnamese business people, like others, sought only to capitalize on their business successes. Many Vietnamese firms and senior executives did just that. Many top tier Vietnamese corporations went onto the stock markets, allowing, for example, a business owner to create fortune selling his equity after three months, rather than the normal ten years it would have taken earlier.

Although many Vietnamese firms went public as the stock market boomed, before going public, most corporations sought strategic, usually international, partners. The most sought after strategic partners were foreign investment funds, international financial institutions, and multinational corporations. Such situations provide yet another place where the mismatch between what foreigners need to understand and what they think they know may cause problems when they seek to conduct business in a country like Vietnam.

On the one hand, the foreign strategic partners bring to the potential collaboration significant financial resources, advanced technologies, and management knowledge. They offer what a local enterprise needs to transform into a regional and even international conglomerate. In addition, having international partnerships pushes the brand name of the Vietnamese corporation to a higher level, which results in increasing prices for the corporation's equities. Also, in that heady period of the stock market growth, other more varied influences from outside the country flooded in, including a small Indian film called "Slumdog Millionaire." In a film-going Vietnam society, many saw the Indian movie and believed that if a "slumdog" in India could become millionaire, so too should a Vietnamese business person be able to create a multi-million dollar business. During that time, several stories of entrepreneurs in Vietnam emerged, further fueling the desire to grow fast. Mr. Dang Le Nguyen Vu of Trung Nguyen Coffee (the "Starbucks of Vietnam) and Mr. Le Phuoc Vu of the Hoa Sen Group each started with "empty hands," as so called "slumdogs," and built very large successful Vietnamese firms. Thus, many Vietnamese came to believe that by providing successful entrepreneurs with more resources, they could create multi-million dollar businesses, which, of course, promised more jobs and opportunities for employment. Because those resources include advanced 
technology, management experience, access to international markets and capital, the foreign strategic partners were viewed as the gold mines to such growth. To this end, Vietnamese corporations sought international strategic partnerships for their long-term development and prosperity.

Understanding what "strategic partnerships" mean for Vietnamese, then is one of the most challenging issues that foreigners face. Sometimes, a strategic partner is viewed as a person who shares a long-term business development plan and core values for building the organization. Sometimes, a strategic partners is someone or an organization that a Vietnamese corporation needs in the short-term for branding or to generate higher equity prices.

On the other hand, the Vietnamese corporations may not in fact need long-term strategic partnerships with foreigners as much as might initially appear to be the case. Some Vietnamese CEO's consider the involvement of a foreigner in the company's board of management more as show than for true contribution Essentially, the Vietnamese firm may argue that the partnership is "good" if the stock prices rises; if it does not, then the partnership may be perceived as unnecessary.

The lesson from this on-off thinking on the part of the Vietnamese is that a potential foreigner partner should try to get at the fundamental reasons and expectations for any strategic collaboration in Vietnam. The case of FPT (Vietnam's largest Internet provider and one of the largest software providers), Texas Pacific Group (TPG)/Intel Capital offers an example of a successful partnership. The Vietnamese and American sides both enjoyed high profits when the price of FPT stock went up significantly in the first quarter of 2007. Intel and TPG gained because they understood the game: they put money into FPT, waited until the "lock up" time expired (forbidding stock sales), then sold their stocks and made profit. They did not try to get involved in FPT's management or stay with FPT for the long-term.

Entrepreneurship has been critically important for both prosperity and sustainability of the Vietnamese economy in the long-run. In fact, many Vietnamese business owners consider going public, listing their companies, and making strategic partnerships, acquisitions or mergers as a successful way to exit their business careers and move on. The 2007-08 period was high season for mergers and acquisitions in Vietnam. There were 51 acquisition and 59 merger transactions considered successful in 2007 and 2008, respectively, more than a half of all mergers and acquisitions from 1995 to 2009 (Vuong et.al., 2010).

Therefore, if a foreign partner is willing to provide a Vietnamese business owner with finance, technology, and management resources to make the business a further success - the foreigner needs to understand the goals of the Vietnamese entrepreneur. For example, the Vietnamese partner may present high interest in expansion plans but, first and foremost, a portion of his business has to transform (very quickly) into cash. If it does not, the Vietnamese partner may soon exit, leaving the foreigner once again baffled, or worse.

\section{Final Observations}

Doing business in an emerging country like Vietnam is seductive for many foreigners. The lure of huge potential gains in an economy with growth that far outpaces any western industrialized one, the optimism of the local business society, and the exotic cultures all can draw like a warn ocean. Yet, not to carry the metaphor too far (!), below the enticing surface can be many riptides, unexpected currents, and perhaps even sharks. Thus, the foreigner seeking to enter a country like Vietnam needs to push far further to understand what the situation is before moving forward. Our observations focus on several arenas in which foreigners may, in all of their open honesty and goodwill, simply misunderstand or misread a situation that could cause problems. None of these conditions assume that there is a concerted effort to scam or dupe a foreigner; they are simply "need to know" guidelines for reducing the expected bafflement that comes with entering a new country to do business. 


\section{References}

--- Global investors have great expectations for emerging markets, 15 September 2010. http://www.ukti.gov.uk/uktihome/media/pressRelease/117708.html)

Bjorkman, I. and Ehrnrooth, M. 1999. HRM in Western Subsidiaries in Russia and Poland, Journal of East-West Business, 5 (3): 63-79.

Giroud, A. 2007. MNEs vertical linkages: The Experience of Vietnam after Malaysia, International Business Review, 16: 159-176.

Harvey, M., Kiessling, T. and Novicevic, M. (2003). Staffing marketing positions during global hyper competitiveness: A market-based perspective. International Journal of Human Resource Management, 14, 223-245.

Miesing, P., Kriger, M.P., and Slough, N. 2007. Towards a model of effective knowledge transfer within transnationals: The case of Chinese foreign invested enterprises, Journal of Technology Transfer, 32: 109-122.

Napier, N.K. (2006). Cross-cultural learning and the role of reverse knowledge flows in Vietnam, International Journal of Cross-Cultural Management, 6 (1), 47-64.

Napier, N.K. (2005). Knowledge transfer in Vietnam: Starts, Stops and Loops, in Journal of Managerial Psychology, 20 (7), 621-636.

Napier, N.K. and Thomas, D. C. (2004). Managing Relationships in Transition Economies. Westport, CT: Praeger Publishers.

Napier, N.K., Harvey, M. and Usui, K. (2008). Management Education in Emerging Economies: An Impossible Dream? Journal of Management Education, 32, (6):92-819

Nguyen, T.V., Giang, C.T.H., and Napier, N.K. 2001. Entrepreneurial Strategic Orientation and Environmental Uncertainty: Vietnam's Small and Medium Sized Enterprises Face the Future, Journal of Asian Business, 17 (3): 71 87.

Prahalad, C.K. 2004. The Fortune at the Bottom of the Pyramid. Philadelphia: Wharton Business School Publishing.

Quang, T., Swierczek, F.W., Chi, D.T. 1998. Effective leadership in joint ventures in Vietnam: A cross-cultural Perspective, Journal of Organizational Change Management, 11 (4), 357-368.

Thomas, D.C. and Ravlin, E.C. 1995. Responses of workers to Cultural Adaptation by a Foreign Manager, Journal of Applied Psychology, 80 (1): 133-146.

Vance, C.M. and Paik, Y. 2005. Forms of host-country national learning for enhanced MNC absorptive capacity, The Journal of Managerial Psychology, 20 (7), 590-606.

Vance, C.M. and Paik, Y. 2002. One size fits all in expatriate pre-departure training? Comparing Mexican, Indonesian and US Workers, The Journal of Management Development, 21, (7/8), 557-571.

Vo, A.N. 2009. Career development for host country nationals: A case of American and Japanese Multinational Companies in Vietnam, The International Journal of Human Resource Management, 20, (6), 1402-1420.

Vu, T.V. and Napier, N.K. 2000. Paradoxes in Vietnam and the United States: Lessons Earned: Part II. In Human Resource Planning Journal, 23, (2), 9-10. 
Vuong, Q.H. 2010. Financial Markets in Vietnam's Transition Economy: Facts, Insights, Implications. ISBN-13: 978-3-639-23383-4, VDM Verlag Aktiengesellschaft \& Co. KG, February 2010, D-66123 Saarbrücken, Germany.

Vuong, Q.H. and Tran , D.T. 2009a. Financial turbulences in Vietnam's emerging economy:

Transformation over 1991-2008 period. In Jagadeesha and Shivakumar Deene (Eds) Contemporary Issues in Finance, 43-61. Excel Books, Delhi, 2009.

Vuong, Q.H. and Tran, T.D. 2009b "The Cultural Dimensions of the Vietnamese Entrepreneurship," The IUP Journal of Entrepreneurship Development, 6 (3 \& 4), 54-78

Vuong, Q.H. and Tran, T.D., and Nguyen, T.C.H. 2010. Mergers \& Acquisitions Market in Vietnam's Transition Economy, The Journal of Economic Policy and Research, 5, (1), 1-54. 